\title{
Onze teses sobre a relação entre psicologia edu- cacional e pedagogia escolar
}

\author{
Giselle Modé Magalhães \\ Universidade Federal de São Carlos (Brasil) \\ Lígia Márcia Martins \\ Universidade Estadual Paulista (Bauru - Brasil)
}

\section{Resumo}

O objetivo do presente texto é problematizar a relação entre a ciência psicológica - em sua subárea educacional - e a ciência pedagógica, destinada às instituições escolares, em seus subsídios ao trabalho pedagógico. À luz do aporte metodológico materialista dialético e por meio de um estudo bibliográfico, colocamos em tela o enfoque histórico-cultural naquilo que a natureza do ensino desenvolvente advoga, isto é, intencionalmente, projetado para a promoção do desenvolvimento omnilateral dos indivíduos. Consideramos que este postulado culmina na necessidade de aclaramento acerca da identidade e especificidades das referidas ciências ao terem a escola como locus de suas implementações práticas. Para tanto, temos as contribuições de Dermeval Saviani em seu texto Onze teses sobre educação e política como eixo organizativo deste artigo. Por analogia ao estudo de Saviani, apresentamos aqui onze teses sobre a relação entre psicologia educacional e pedagogia escolar, as quais analisam as especificidades e semelhanças de cada uma destas ciências, assim como as posiciona na prática social. Concluímos com uma unidade mínima de análise, qual seja: é a psicologia educacional que se subordina à pedagogia escolar, e não o contrário.

Palavras-chave: Psicologia educacional. Pedagogia escolar. Pedagogia histórico-crítica. Psicologia histórico-cultural.

\section{Eleven theses on the relationship between educational psychology and school pedagogy}

\section{Abstract}

The aim of this paper is to problematize the relationship between psychological science - in its educational subarea - and pedagogical science, aimed at school institutions, in its subsidies to pedagogical work. In light of the dialectical materialist methodological input and through a bibliographical study, we put the historical-cultural perspective on what the nature of developmental teaching advocates, that is, intentionally designed to promote the omnilateral development of individuals. We consider that this postulate culminates in the need to clarify the identity and specificities of these sciences by having the school as the locus of their practical implementations. For this purpose, we have the contributions of Dermeval Saviani in his text Eleven theses on education and politics as the organizational axis of this article. By analogy to Saviani's study, we present here 
Onze teses sobre a relação entre psicologia educacional e pedagogia escolar

eleven theses on the relationship between educational psychology and school pedagogy, which analyze the specificities and similarities of each of these sciences, as well as position them in social practice. We conclude with a minimum unit of analysis, which is: it is educational psychology that is subordinate to school pedagogy, not the other way around.

Keywords: Educational psychology. School pedagogy. Historical-critical-pedagogy. Historicalcultural psychology.

\section{Once tesis sobre la relación entre la psicología educativa y la peda- gogía escolar}

\section{Resumen}

El objetivo de este artículo es problematizar la relación entre la ciencia psicológica, em su subárea educativa, y la ciencia pedagógica dirigida a las instituciones escolares, en sus subsidios al trabajo pedagógico. A la luz del enfoque metodológico materialista dialéctico y a través de un estudio bibliográfico, ponemos el enfoque histórico-cultural en lo que la naturaleza de la enseñanza para el desarrollo defiende, es decir, diseñada intencionalmente para promover el desarrollo omnilateral de los individuos. Consideramos que este postulado culmina en la necesi2 dad de aclarar la identidad y las especificidades de estas ciencias al tener a la escuela como el lugar de sus implementaciones prácticas. Por lo tanto, tenemos las contribuciones de Dermeval Saviani em su texto Once tesis sobre educación y política como eje organizativo de este artículo. Por analogia com el estudio de Saviani, presentamos aquí once tesis sobre la relación entre la psicología educacional y la pedagogía escolar, que analizan las especificidades y similitudes de cada una de estas ciencias y las posicionan en la práctica social. Concluimos con una unidad mínima de análisis, a saber: es la psicología educativa que está subordinada a la pedagogía escolar, y no al revés.

Palabras clave: Psicología educacional. Pedagogía escolar. Pedagogía histórico-crítica. Psicología histórico-cultural.

\section{Introdução}

Não temos de pronto uma afirmação que possa definir o questionamento que faremos, como tinha Saviani (200 1) ao escrever sobre educação e política, qual seja, o de que a educação é sempre um ato político. Mas podemos afirmar que temos nos deparado frequentemente com situações dentro das escolas, nas quais professores recorrem à psicologia como solução para os problemas da educação e, igualmente, com profissionais da psicologia 
educacional que dispensam as teorias pedagógicas, valorizando sobremaneira a psicologia em detrimento da pedagogia. Partimos, então, do problema da especificidade e interfaces entre essas áreas do saber no campo escolar e educacional para realizar a análise, ora empreendida, que objetiva encontrar as relações internas e externas entre essas ciências. E, com isso, se não temos a referida afirmação como ponto de partida, pretendemos tê-la como produto desta análise.

Para tal, nos valemos do método materialista dialético, estofo do enfoque histórico-cultural, que advoga a necessidade de superação da captação dos fenômenos em sua aparência, tendo em vista, pela mediação da análise, depreender sua essencialidade concreta, não dada à apreensão imediata. Sendo assim, por meio de um estudo bibliográfico, buscamos desvelar as relações internas essenciais entre psicologia educacional e pedagogia escolar, a partir do destaque aos objetos e especificidades de cada uma delas.

Inicialmente, apresentamos o pressuposto que existem especificidades no interior de cada uma destas ciências, as quais visamos explicitar por analogia ao procedimento lógico-conceitual percorrido por Saviani (2001), que dá título ao presente artigo: Onze teses sobre a relação entre psicologia educacional e pedagogia escolar. Entretanto, para que o leitor nos acompanhe nesse exercício lógico-conceitual, faz-se importante apresentar o nosso ponto de partida, qual seja, a unidade dialética entre ensino e desenvolvimento. Grosso modo, essa assertiva postula ensino e desenvolvimento como polos distintos, porém inseparáveis, na formação humana, já que todo desenvolvimento conterá por interioridade os processos de ensino e estes, por seu turno, assentar-se-ão nos alcances do desenvolvimento. É a partir da compreensão desta unidade que poderemos explicitar a identidade e especificidades das ciências ora em foco e, consequentemente, a sua indissociabilidade.

Lev S. Vigotski (2001), autor eminentemente reconhecido dentro da psicologia histórico-cultural, evidenciou que o desenvolvimento humano acontece por meio dos processos de ensino, ou, em outras palavras, que são os processos de ensino que promovem o desenvolvimento humano. Isso significa, em conformidade com a lógica dialética que sustenta os estudos do referido autor, que um processo não acontece na ausência do outro: tanto o ensino promove desenvolvimento, quanto o desenvolvimento consolidado lou na iminência de consolidar-se) permite a incidência do ensino. 
Onze teses sobre a relação entre psicologia educacional e pedagogia escolar

Ainda segundo os pressupostos vigotskianos, evidencia-se, como apresentado por Magalhães e Martins (2018), que os processos de ensino pelos quais os indivíduos se submetem ao longo de sua vida estão contidos no desenvolvimento humano, assim como no processo de ensino estão contidas as possibilidades de desenvolvimento concreto em cada momento histórico da vida de cada pessoa. É com este entendimento que afirmamos o ensino e o desenvolvimento como unidade de contrários, ou como polos opostos interiores um ao outro, de modo que um polo afirma sua existência pela presença de seu contrário. Ou seja, só há desenvolvimento se houver ensino, assim como só há ensino se houver aprendizagem.

Antes de prosseguir, faz-se necessário uma pequena ressalva. Longarezi e Puentes (2017), optaram pelo uso do termo em russo em sua forma transliterada obutchénie (desenvolvimento) ao tratar da unidade ensino-aprendizagem-desenvolvimento, uma vez que afirmam não existir em português uma tradução que represente o significado adequado que o ensino tem dentro da psicologia histórico-cultural, qual seja, "[...] a unidade constitutiva da atividade docente que encerra tanto a atividade didática do professor quanto a atividade de autotransformação dos alunos" (LONGAREZI; PUENTES, 2017, p. 7). No entanto, entendemos que a compreensão dialética do processo de ensino nos permite o uso do vocábulo em português. Para tal, recorremos ao conceito de trabalho, a pressupor a unidade entre processo e produto. No caso do trabatho pedagógico o processo está para o ensino tanto quanto o produto está para a aprendizagem, ou seja, a aprendizagem é produto do ensino e, se não houve aprendizagem, é porque não houve ensino.

Não é difícil entender que os processos interpsíquicos se transmutam em processos intrapsíquicos por internalização. $\bigcirc$ ensino se apresenta na alçada interpsíquica como meio para internalização objetivada, intrapsiquicamente, sob a forma de conteúdo aprendido. $\bigcirc$ que precisamos é extrair da unidade dialética maior, representada pelos polos ensino-desenvolvimento, uma outra unidade menor, representada pelos processos de ensino e aprendizagem. Ao entendermos essa unidade de contrários, não descolaremos o ensino da aprendizagem, e a díade ensino-desenvolvimento converte-se na tríade ensino-aprendizagem-desenvolvimento.

Feita esta observação, retomamos a unidade ensino-aprendizagem-desenvolvimento, para a qual Martins (2013) recorre ao preceito lógico-dialético da dinâmica entre quantidade e qualidade, afirmando que 
é a "quantidade" de aprendizagens resultantes do ensino que qualificam o desenvolvimento, ao mesmo tempo em que a "quantidade" de desenvolvimento edificada pelas aprendizagens descortina novas possibilidades para os avanços do ensino.

No entanto, Vygotski (2001) foi claro ao afirmar que não é qualquer ensino que promove desenvolvimento, encaminhando-se na direção de uma necessária distinção entre o ensino pautado em conceitos espontaneamente formados pela simples inserção social, e o ensino fundamentado em conceitos metódicos, cientificamente formulados e convertidos em conteúdos escolares. Apesar desta ser uma questão já bastante explorada pela psicologia histórico-cultural, cabe questionarmo-nos: mas afinal, o que é desenvolvimento promovido pelo ensino de conceitos científicos? E recorremos às palavras do próprio Vigotski, traduzido por Prestes e Tunes (2018), para responder:

Penso que vocês concordarão comigo se eu disser que o aspecto mais importante que faz com que o desenvolvimento seja desenvolvimento, que the atribui uma qualidade sem a qual não pode ser chamado de desenvolvimento, é o surgimento do novo. Se diante de nós, temos um processo no decorrer do qual não surge nenhuma nova qualidade, nenhuma nova particularidade, nenhuma nova formação, então é claro, não podemos falar em desenvolvimento no sentido próprio dessa palavra (PRESTES; TUNES, 2018, p. 33).

E, ainda se referindo ao que seja desenvolvimento, Prestes e Tunes (2018) também afirmam a necessidade de que o compreendamos não apenas como processo progressivo, que segue sempre em frente, mas sim, como um processo no qual toda evolução seja também a involução daquilo que the antecedeu, ou o que o autor denomina de desenvolvimento reverso. Por exemplo, a fala desconstrói o balbucio; os interesses do escolar descontroem os interesses do pré-escolar etc.

Deste modo, conforme o autor, temos que o ensino de conceitos científicos supera qualitativamente aquele pautado em conceitos cotidianos, já que os primeiros exigem e articulam processos psicofísicos intrapsíquicos mais complexos, a exemplo da atenção voluntária; das operações lógicas do pensamento, a saber, análise e síntese, comparação, generalização e abstração; e da memória lógica, dentre outros que pressupõem o autodomínio da conduta. 
Onze teses sobre a relação entre psicologia educacional e pedagogia escolar

Pelos estudos de Vigotski (2001), a aprendizagem de conceitos científicos transforma a relação do sujeito em face do objeto, uma vez que tais conceitos são sempre mediados por inúmeros outros conceitos, configurando-se em um sistema conceitual, dado que apresentará o objeto ao pensamento de forma multilateral, isto é, como síntese de múltiplas determinações. Mas, para tanto, há que se identificar como conteúdo interno da aprendizagem de sistemas conceituais a captação, pelo aprendiz, das relações que subjazem entre os diferentes objetos e fenômenos representados como conceitos, tarefa esta subjugada ao alcance do pensamento adjetivado como "teórico", rigorosamente abstrato.

Em última instância, o que o autor colocou em destaque em relação à educação escolar diz respeito ao alcance da capacidade de análise do pensamento e a conquista da autorregulação do comportamento nela consubstanciada e, nesse diapasão, conferiu grande importância à organização do ensino apto a tais promoções. O ensino desenvolvente é, portanto, aquele que prima pelas aprendizagens que promovem transformações nas representações, pelos sujeitos, dos objetos e fenômenos dados à captação empírica. Estas transformações, por seu turno, resultam do fato de que entre sujeito e objeto 6 interpõem-se os sistemas conceituais, que, por esta via, requalificam os conteúdos da consciência.

Desta forma, o ensino desenvolvente visa promover a organização de sistemas conceituais científicos na consciência de cada indivíduo, o que permite a este direcionar suas ações no mundo para além de si mesmo, ou seja, em unidade com a universalidade. Concordamos com Longarezi e Franco (2017, p. 270), que o processo educativo precisa "se constituir em objetivação genérica "para si", promovendo o desenvolvimento de individualidades "para si". Foge às possibilidades deste texto uma discussão aprofundada sobre o conceito de individualidade "para si" , mas se faz necessário pontuar a importância desse horizonte formativo para a educação escolar que vise a transformação social.

Diante do exposto, nos encaminhamos para um tratamento mais pontual acerca da indissociável relação entre a ciência psicológica e a ciência pedagógica no ensino desenvolvente, com destaque aos distintos objetos de cada uma delas, conteúdo este que conferirá legitimidade às teses a serem apresentadas ao longo do texto. 


\section{Psicologia educacional e pedagogia escolar: ciências indispensáveis ao ensino desenvolvente}

Inicialmente é preciso ter a clareza que a psicologia educacional e a pedagogia escolar são ciências distintas, embora inseparáveis quando estudamos o ensino desenvolvente e esta afirmação nos conduzirá às oito primeiras teses deste estudo. Para sustentar esta afirmativa, trazemos a obra de Vasily V. Davídov, pesquisador russo que se dedicou aos problemas do ensino que promovem desenvolvimento. Davídov (1986) nos apresenta os estudos de Rubinstein para esclarecer que a ciência psicológica e a ciência pedagógica trazem objetos de estudos distintos, porém internamente condicionados. Em outras palavras, o objeto de estudo da psicologia - desenvolvimento psíquico - é condição para a atuação pedagógica e vice-versa: o objeto de estudo da pedagogia - o ensino - é condição para a promoção do desenvolvimento. Seguem as palavras do próprio autor:

Embora tenha enfatizado a unidade interna entre o desenvolvimento e o processo pedagógico, Rubinstein também observou os diferentes enfoques utilizados pelas ciências psicológica e pedagógica. $\bigcirc$ objeto da psicologia são as leis do desenvolvimento mental da criança e, deste ponto de vista, o processo pedagógico é a condição desse desenvolvimento. O objeto da pedagogia são as leis específicas da educação e do ensino; aqui, as propriedades mentais da criança, nos vários estágios de seu desenvolvimento, são meramente condições que devem ser levadas em consideração. 'O que para uma destas ciências é objeto, para outra atua como condição' (DAVÍDOV, 1986, p. 59).

Com essa citação, evidencia-se a não-identidade entre essas ciências, uma vez que cada uma possui objeto de estudo específico, o qual deve orientar a ações distintas em face do ensino desenvolvente. E aqui temos a primeira tese, qual seja: não existe identidade entre psicologia educacional e pedagogia escolar.

A eleição de dado objeto de estudo condiciona, por sua vez, a adoção de um método, a balizar os procedimentos investigativos que as diferentes ciências levam a cabo. Portanto, toda diferença de objeto não deixa de ser uma distinção objeto-metodológica. Ademais, já que o objeto de qualquer ciência diz respeito aos aspectos e fenômenos da realidade que se visa 
Onze teses sobre a relação entre psicologia educacional e pedagogia escolar

decodificar cientificamente por meio de determinado método e procedimentos, se duas ciências assumirem a mesma orientação objeto-metodológica com certeza uma delas será desnecessária. Por isso, entendemos equivocada a centralidade muitas vezes conferida a teorias psicológicas em detrimento de uma teoria pedagógica, ainda que sob o enfoque histórico-cultural os fenômenos devam ser apreendidos como sínteses de múltiplas determinações.

Os profissionais da psicologia educacional voltam seu olhar para o desenvolvimento humano, avaliando as diferentes manifestações desse processo; enquanto os pedagogos efetivam o desenvolvimento, ao identificar e transmitir os conteúdos escolares necessários em cada momento da vida, organizando-os às melhores formas de ensino.

O leitor que acompanha nosso raciocínio até aqui deve concordar que não é possível dissociar a atuação da psicologia educacional e da pedagogia escolar quando investigamos o ensino desenvolvente. Em toda prática da psicologia educacional existe uma dimensão pedagógica, uma vez que, ao avaliar e compreender o processo de desenvolvimento, os psicólogos educacionais também identificam o ensino ali contido (MAGALHÃES, 2016). E o contrário também é verdadeiro, pois dentro da prática pedagógica há 8 uma dimensão da psicologia educacional, já que o processo de desenvolvimento, seus reais alcances e as suas possibilidades iminentes estão contidos na organização do ensino, ou melhor, se expressam e condicionam a prática pedagógica. Trata-se, portanto, de uma relação interna de mútua condicionabilidade dessas ciências, na qual apoiamos a segunda e a terceira tese: toda prática da psicologia educacional contém uma dimensão pedagógica escolar; e toda prática pedagógica escolar contém inevitavelmente uma dimensão da psicologia educacional.

Outro aspecto digno de nota, tal como Saviani (200 1) apontou para a relação entre educação e a política, também existe entre a psicologia educacional e a pedagogia escolar numa relação externa, qual seja, o desenvolvimento da prática, especificamente psicológica, pode abrir novas perspectivas para o desenvolvimento da prática pedagógica e vice-versa. Isso significa que quanto mais a psicologia educacional compreender o processo de desenvolvimento humano e todas as suas peculiaridades, maiores serão as suas contribuições para o trabalho pedagógico e, quanto mais desenvolvido o trabalho pedagógico, melhor será sua contribuição para o desenvolvimento humano. A título de exemplo para tal assertiva, podemos tomar que perscrutar a periodização do 
desenvolvimento psíquico, no que tange à construção de motivos para a aprendizagem, pode corroborar para a maior adequação entre o planejamento do ensino e as atividades que guiam o desenvolvimento. Igualmente, uma prática pedagógica pautada em tais atividades pode abrir possibilidades para a descoberta de novas particularidades edificadas histórico-culturalmente. Portanto, se essas práticas são distintas (primeira tese), mas inseparáveis (segunda e terceira tese), então, a natureza que se estabelece na relação entre psicologia educacional e pedagogia escolar é de condicionabilidade recíproca.

Assim, ao explicitar o que é específico de cada uma dessas ciências na esteira da unidade dialética entre ensino e desenvolvimento, não se pode perder de vista a não identidade entre as especificidades de atuação do psicólogo educacional e do pedagogo neste processo. A psicologia traz um suporte fundamental sobre o processo de desenvolvimento humano promovido pelas ações pedagógicas, no entanto, as leis do ensino, seus conteúdos e formas de transmissão são tarefas do pedagogo. Somente com a clareza de tais especificidades é que podemos compreender a dimensão psicológica da prática pedagógica e a dimensão pedagógica da prática psicológica educacional, como descrito anteriormente. Assim como postulam a quarta e a quinta tese, a saber: a explicitação da especificidade da prática da psicologia educacional junto à prática pedagógica escolar se realiza à medida em que ela subsidia o ensino - objeto pedagógico; a explicitação da especificidade da prática pedagógica escolar em relação à psicologia educacional se realiza à medida em que ela promove o desenvolvimento - objeto da psicologia.

Ou seja, ao instrumentalizar a atividade docente teórico-metodologicamente, no que tange aos preceitos psicológicos implicados na aprendizagem, é que a psicologia educacional corrobora com o ato de se ensinar. E, ao ensinar, a atividade pedagógica escolar corrobora com a promoção do desenvolvimento. Sendo assim, a especificidade de tais práticas subjugam-se à dimensão objeto-metodológica das ciências que as validam, não obstante existirem entre elas um tipo especial de relação que, a nosso juízo, pode ser ilustrado pelo princípio gestáltico da dinâmica figura-fundo. Daí que a sexta e sétima teses sejam: a especificidade da prática pedagógica escolar define-se pelo seu objeto de estudo - as leis de ensino, quando conteúdo e forma se apresentam como figuras sobre o fundo representado pelo destinatário ; e a especificidade da prática da psicologia educacional define-se pelo seu objeto de estudo - as leis do desenvolvimento psíquico, quando o destinatário se 
Onze teses sobre a relação entre psicologia educacional e pedagogia escolar

apresenta como figura sobre o fundo conteúdo e forma consubstanciados no ensino.

Deduz-se, até aqui, a relação interna e externa entre essas ciências, as quais nos indicam uma autonomia relativa e uma dependência recíproca, como sistematizado na oitava tese: as relações entre psicologia educacional e pedagogia escolar dão-se na forma de uma autonomia relativa e dependência recíproca.

Por outro lado, se recuperamos os pressupostos históricos do advento das ciências em geral nos primórdios da sociedade moderna, temos que entender que foram as demandas da prática social que exigiram e impulsionaram a busca pela decodificação abstrata da realidade concreta sob a forma de teorias. Não por acaso, ao considerar a relação entre educação e política, Saviani (2001) colocou em destaque a relação histórica entre essas duas ciências, uma vez que ambas são manifestações sociais, e, portanto, condicionadas às especificidades de cada momento histórico. Transpondo essa assertiva para a relação entre psicologia educacional e pedagogia escolar não podemos perder de vista que ambas são modalidades específicas que expressam uma mesma realidade, ou seja, que integram a totalidade social.

10 Por isso, não podemos compreender a prática pedagógica e a prática da psicologia educacional descolando-as da sociedade que as fizeram e as fazem necessárias, não podemos excluir de nossa análise questões sobre essa sociedade: quais as suas demandas históricas, e quais as demandas que nos trazem no tempo presente.

Ou seja, é preciso historicizar a relação entre essas ciências, mas não sem a clareza de que as ciências modernas despontaram sob a hegemonia lógico-formal, instituinte dos enfoques dicotômicos que não raro se impõem como obstáculos para a compreensão da essência concreta dos fenômenos, e que ainda se encontra fortemente presente nas ciências modernas. Apenas reiteramos que todo o raciocínio que apresentamos sobre a relação entre psicologia educacional e pedagogia escolar até este momento foi construído sob outra lógica, contra-hegemônica, a lógica dialética, que supera por incorporação a lógica formal justamente para compreender os fenômenos em sua totalidade. 


\section{Historicizando as relações entre psicologia e pedagogia no Brasil}

A psicologia no Brasil desponta no interior da educação, não só porque as antigas escolas normais tinham em seus currículos a matéria de Psicologia e, portanto, receberam os primeiros laboratórios de psicologia, mas também porque os problemas educacionais demandavam respostas no âmbito do desenvolvimento do indivíduo, tais como os problemas de aprendizagem, o relacionamento com a família, a formação da personalidade, as crianças "difíceis" etc. (ANTUNES, 2003). Foram as demandas das escolas e suas investigações sobre os comportamentos e o desenvolvimento dos indivíduos que impulsionaram a criação dos cursos de formação de psicólogos, como afirmam Souza e Cunha (2010). Isso significa que a psicologia nasce no Brasil atendendo às demandas da educação, que, por sua vez, atendia também às demandas da modernização do país, pois era preciso educar e formar um "novo homem", apto a estabelecer novas relações de trabalho, especialmente nas indústrias que fortaleciam o sistema capitalista (ANTUNES, 2003)

Já o curso de Pedagogia surge no Brasil no final da década de 1930, atrelado ao movimento de criação das primeiras universidades brasileiras. A necessidade era de formação de professores para as escolas públicas de ensino básico e o objetivo era formar bacharéis (que cumpriam a grade do curso em 3 anos) e licenciados em pedagogia (que cumpriam os 3 anos do curso mais 1 ano do curso de didática), ou seja, havia uma separação entre os profissionais que atuariam em cargos técnicos e os que iriam lecionar (BRZEZINSKI, 1996).

Saviani (2012, p. 34) descreve que a formação de professores tinha um caráter profissional, "[...] desvinculada do desenvolvimento de pesquisa [...]", assim como Brzezinski (1996) aponta que o curso de pedagogia, em suas origens, foi marcado por um pragmatismo cuja origem encontra-se na sua centralização profissionalizante, deslocado de centros de pesquisa e produção do conhecimento, o que tornou a pedagogia um campo prático. A autora argumenta que esta origem do curso impediu por muito tempo o desenvolvimento da investigação científica na área, pois o professor passava a dominar métodos e técnicas, mas não se aprofundava em estudos da pedagogia como área do saber. 
Onze teses sobre a relação entre psicologia educacional e pedagogia escolar

A quem competia, então, a produção de conhecimento sobre o objeto da pedagogia? Brzezinski (1996), concordando com os estudos de Luiz Carlos Freitas, afirma que as investigações sobre a pedagogia e o seu próprio desenvolvimento eram realizadas por especialistas das disciplinas de suporte epistemológico e de conteúdos específicos, nas quais, em nosso entendimento, se inclui a psicologia. Inclusive, como nos mostra Saviani (2012), a disciplina de psicologia educacional se destacava na grade dos primeiros cursos de pedagogia, pois era a única que se repetia durante os 3 anos de formação obrigatória e também no curso de didática.

Não vemos mais esta fragmentação nos cursos de pedagogia atualmente, nem mesmo a referida organização curricular, mas concordamos com Brzezinski ( 1996) que os cursos de pedagogia ainda sentem as consequências não só do pragmatismo inicial e da produção de conhecimentos, pautada por outras áreas, como também de uma desvalorização histórica que ainda marca nossos estudantes. "O curso de pedagogia foi ocupando lugar periférico no contexto das licenciaturas que já eram periféricas no elenco dos demais cursos superiores, porque percebidas como cursos de segunda categoria" (BRZEZINSKI, 1996, p. 44).

12 Seguramente é a prática social do conjunto dos homens e mulheres que determina e os contextos históricos que condicionam a ação do psicólogo e do pedagogo. Por isso, ao historicizar a relação entre essas ciências, pudemos avançar nos objetivos deste estudo e afirmar que a psicologia educacional vem ocupando historicamente um espaço dentro da produção do conhecimento pedagógico que foi deixado pela própria pedagogia, mas que cabe à esta dominar.

Dentro da própria psicologia histórico-cultural temos um campo de conhecimento consolidado sobre a didática desenvolvente, a qual, segundo Puentes e Longarezi (2017), surge na ex-União Soviética sob a influência da filosofia, da fisiologia, da pedagogia e da psicologia, porém, é a psicologia que interferiu e ainda interfere de maneira decisiva na didática, dizem os autores.

Podemos ainda observar que, quando chamada para dentro das escolas, a psicologia historicamente utiliza modelos clínicos, pautada em psicodiagnósticos, em psicoterapias, e na psicometria para, em grande medida, patologizar e medicalizar cada vez mais nossas crianças (FIRBIDA; 
VASCONCELOS, 2019). Modelo de atuação este que, desde a década de 1970, recebe diversas críticas por desconsiderar o contexto em que se produz o desenvolvimento humano, ou o contexto em que se produz os problemas no desenvolvimento humano, ou ainda, sem considerar o processo de ensino que promoveu o desenvolvimento humano.

Certamente Maria Helena de Souza Patto (1996), junto com um coletivo de autores, é uma importante referência ao afirmar, na década de 1980, os fatores sociais que produzem o fracasso escolar, desestimulando a rotulação, a estigmatização e a culpabilização do indivíduo que eram reflexo do modelo clínico. No entanto, os fenômenos não desaparecem por completo na história, e o modelo clínico não só continua atual dentro das escolas, como tende a se fortalecer diante do acirramento da organização liberal em nossa sociedade, que responsabiliza e culpabiliza de maneira crescente os indivíduos pelos seus desempenhos nas diferentes esferas da vida.

Ao refletirmos sobre o atual momento histórico, em que as ideias da classe dominante afirmam o indivíduo dotado de autonomia moral, de sentimentos e desejos próprios, capaz de tomar as suas próprias decisões e gerir sua vida (FIGUEIREDO; SANTI, 2013), então, é o indivíduo que adoece e/ ou fracassa na escola que precisa do atendimento psicológico. Por consequência, é o psicólogo que deve resolver os problemas comportamentais ou de aprendizagem, já que ele é, supostamente, o profissional destinado a identificar e intervir junto a cada indivíduo, tendo em vista, lamentavelmente, sanar funcionamentos desviantes. Dito isso, podemos apresentar a nona tese: a organização do ensino na sociedade de classes tem se caracterizado pela subordinação da pedagogia escolar à psicologia educacional.

Para além de um processo histórico de influência da psicologia no campo pedagógico, a nosso juízo, a grande penetração da psicologia histórico-cultural no campo da educação escolar brasileira não deixa de ser uma via para a superação do cenário descrito, posto que esta teoria, ao colocar em relevo as leis psicológicas que regem os processos de ensino e aprendizagem, os aspectos psicológicos presentes na prática pedagógica e em suas expressões didáticas, a importância da relação professor-aluno, bem como da adequada organização institucional da escola, assevera a natureza social da formação humana. Contudo, não obstante suas incontestes contribuições para a educação escolar, não temos acordo de que ela, tomada isoladamente, possa ser sua referência nuclear, usurpando o lugar de uma teoria pedagógica. 
Onze teses sobre a relação entre psicologia educacional e pedagogia escolar

Destarte, ancorando-se no materialismo histórico-dialético é fato que a psicologia histórico-cultural - em sua subárea educacional, não se compatibiliza com quaisquer teorias pedagógicas, carecendo, pois, de afinidades com uma pedagogia compatível com seus preceitos. Nessa direção é que Martins (2013) afirma a unidade entre a psicologia histórico-cultural e a pedagogia histórico-crítica, haja vista a afinidade filosófica entre ambas, bem como a defesa que fazem de uma educação escolar deveras desenvolvente. Para estas teorias, não são quaisquer modelos pedagógicos que se colocam a serviço da formação omnilateral dos indivíduos, isto é, que operam transformações no ser hominizado - que dispõe de propriedades naturais filogeneticamente formadas, em um ser humanizado - produto e produtor da cultura de quem passa a depender. Nas palavras de Saviani (2001 , p. 13): "[...] o que não é garantido pela natureza tem que ser produzido historicamente pelos homens, e aí se incluem os próprios homens [...]", sendo esta a tarefa precípua da educação escolar neste momento histórico.

A pedagogia histórico-crítica, por sua vez, tem sua origem na história da educação brasileira, segundo Dermeval Saviani, embora, na atualidade consolide-se como uma construção teórica coletiva e, notadamente, contra

14 hegemônica. Da mesma forma que a psicologia histórico-cultural edifica-se com base no materialismo histórico-dialético, não perdendo de vista a natureza social do desenvolvimento humano. Podemos afirmar que a pedagogia histórico-crítica e a psicologia histórico-cultural encontram-se em torno de um ideal comum: a formação de um novo homem, apto à construção de novos tempos, a pressupor a superação da sociedade burguesa.

Sendo assim, não reduz os conteúdos escolares a conceitos de senso comum, adquiridos espontaneamente pela vivência social cotidiana, defendendo que a assunção da tarefa desenvolvente por parte da escola demanda um tipo específico de prática pedagógica, baseada num currículo voltado à transmissão dos conhecimentos historicamente sistematizados e referendados pela prática social ao longo dos tempos - "conhecimentos clássicos" Uma prática pedagógica orientada pelo planejamento intencional e pela sistematização lógica e sequencial dos conteúdos de ensino, tendo em vista que, assegurando as articulações necessárias entre conteúdos e formas de transmissão, promova os melhores efeitos no que tange às aprendizagens dos alunos.

Suas primeiras formulações datam da década de 1980, num contexto de rica efervescência política no Brasil, especialmente no âmbito das políticas 
sociais e, dentre elas, aquelas destinadas à educação escolar. As obras, organizadas por Dermeval Saviani, Escola e Democracia (1 ${ }^{a}$ ed., 1983) e Pedagogia Histórico-Crítica: primeiras aproximações (1991) são marcos referenciais para o amplo arcabouço teórico que hoje caracteriza a pedagogia histórico-crítica.

Tais obras demarcam, dentre outras questões, que a escola, na qualidade de instituição social, é submetida às inúmeras influências dos modos organizativos da sociedade, mas, igualmente, à medida que ela, escola, forma os seres sociais, também opera como vetor determinante da tecitura social. $\bigcirc$ reconhecimento desta reciprocidade confere à educação escolar imensa reponsabilidade no que tange à formação intencional de indivíduos aptos a transformarem a ordem político-econômica vigente. Advogar uma educação escolar pública de qualidade é a marca fundante da pedagogia histórico-crítica, comprometida que é com a socialização das máximas conquistas culturais da humanidade no âmbito da filosofia, da arte e da ciência.

Portanto, a pedagogia histórico-crítica é opositora radical a cenários que desvalorizam o professor e a pedagogia como ciência da educação, cenários que, não raro, promovem o arcabouço teórico da psicologia para primeiro plano. Nessa esteira, profissionais da psicologia educacional, por vezes, se arvoram a detentores de todos os conhecimentos necessários para resolver os problemas da educação escolar, ultrapassando os tênues limites que demarcam a pedagogia escolar e a psicologia educacional como ciências articuladas, mas com especificidades objeto-metodológicas próprias.

Em outras palavras, sob tais condições, em que temos uma hegemonia lógico-formal, acaba por existir uma subordinação da pedagogia escolar em relação à psicologia educacional e, consequentemente, à ciência psicológica, aparentemente detentora do conhecimento sobre o indivíduo, que ganha cada vez mais espaço. Com isso, ignora-se a face oculta do desenvolvimento - os processos educativos - e desvaloriza-se o próprio processo de escolarização. Trata-se do fetiche da individualidade (DUARTE, 2004), com uma exacerbada valorização da psicologia, também conhecido como psicologismo.

Pelo exposto, consideramos que há uma autonomia relativa da prática pedagógica em face da prática psicológica e vice-versa, assim como há uma dependência recíproca de uma ciência para com a outra, conforme já afirmado. No entanto, ao tratar do grau de dependência de uma ciência em 
Onze teses sobre a relação entre psicologia educacional e pedagogia escolar

relação à outra, afirmamos, na contramão da lógica vigente, que a ciência psicológica tem um grau de dependência maior da ciência pedagógica que o contrário. É a psicologia educacional que se subordina à pedagogia escolar, uma vez que são os processos educativos que antecedem o desenvolvimento humano, sem os quais ele não ocorre.

Desta forma, ao buscarmos na prática social representativa da sociedade hodierna os elementos que nos indicam as condições para as ações da psicologia educacional e da pedagogia, não podemos perder de vista que estamos diante, como afirmou Saviani (2001 , p. 85) "[...] de uma sociedade cindida entre interesses antagônicos [...]" e em permanentes disputas. No tocante a isso, temos acordo com Freitas (2018) de que a conciliação de classes não é uma opção para superarmos as inúmeras crises que temos atravessado em decorrência das referidas disputas. O pleno exercício da prática educativa só é possível em um

[...] tipo de sociedade que se delineia no horizonte de possibilidades das condições atuais, mas que não chegou ainda a se concretizar. Isto porque a plenitude da educação como, no limite, a plenitude humana, está condicionada à superação dos antagonismos sociais (SAVIANI, 2001, p. 87).

Trata-se, sem meias palavras, da luta pela construção da sociedade socialista, legado histórico deixado aos homens e mulheres deste tempo, e que não vai acontecer se não nos organizarmos também para além dos muros da universidade. Nesse ínterim, segue a décima tese: superada a hegemonia lógico-formal que pauta a construção do conhecimento na sociedade burguesa, cessa o primado da psicologia educacional e, em consequência, a subordinação da pedagogia escolar à psicologia educacional.

É preciso superar essa sociedade para que possamos avançar na construção dos verdadeiros conhecimentos sobre o ser humano, colocando-os a serviço da formação de todos e de todas. De forma alguma defendemos a sobreposição de uma ciência sobre a outra, mas sim que cada qual se oriente pelo seu próprio objeto, sem perder de vista o ensino desenvolvente. À medida que a pedagogia escolar assume seu lugar na prática social e na produção de conhecimento, realiza-se como prática direcionada às leis do ensino e, então, a psicologia educacional pode cumprir a sua especificidade dentro desta ciência, qual seja, oferecer o aporte teórico sobre os processos de desenvolvimento 
psíquico. $\bigcirc$ que nos leva à décima primeira e última tese: a expressão da psicologia educacional na pedagogia escolar cumpre-se na medida em que esta se realiza como prática especificamente direcionada às leis de ensino.

\section{Considerações finais}

Após trilhar o percurso lógico-conceitual oferecido por Saviani (2001) em seu texto onze teses sobre educação e política, explicitamos também onze teses sobre a relação entre psicologia educacional e pedagogia escolar, das quais retiramos uma síntese provisória para ser debatida, confirmada, ou refutada pelos pesquisadores e profissionais da área, qual seja: é a psicologia educacional que se subordina à pedagogia escolar, e não o contrário. Em nossa concepção, cabe à psicologia educacional fornecer subsídios das pesquisas sobre o desenvolvimento humano à pedagogia escolar, mas não deve se colocar acima desta área do conhecimento como suposta única detentora do saber sobre o ensino desenvolvente.

Tal afirmação justifica-se pela necessidade de que a produção de conhecimento, tão cara à psicologia educacional e à pedagogia escolar, paute-se pelo seu real objeto epistemológico, pela necessidade de que os pedagogos assumam as leis do ensino como objeto de estudo e que os psicólogos educacionais entendam que seu objeto de estudo, o processo de desenvolvimento humano, depende das leis do ensino e, por isso, está subordinado à pedagogia escolar. A psicologia educacional precisa olhar para si mesma e compreender as suas especificidades e os seus limites, uma vez que ainda não resolveu uma série de problemas próprios, como, por exemplo, a afecção do conhecimento sobre o indivíduo concreto, questão recentemente debatida no Simpósio de Psicologia Concreta na UFSCar .

Desta forma, a compreensão do ensino desenvolvente como critério para entender a dialética existente entre psicologia educacional e pedagogia escolar nos ajuda a fazer avançar ambas as ciências juntas na direção da formação de sujeitos revolucionários, uma vez que, se não for para isso, não há razão para este debate. 
Onze teses sobre a relação entre psicologia educacional e pedagogia escolar

\section{Notas}

1 Para evitar desconforto ao leitor, adotaremos nesse texto o uso padrão das regras gramaticais, as quais contribuem para que o gênero masculino seja entendido como representativo do genérico da humanidade. (MIGUEL; BIROLI, 2014). Estamos cientes deste problema, mas esperamos que nossa escolha não signifique menor sensibilidade com a temática.

2 Optamos por adjetivar como pedagogia escolar, tendo em vista as demais áreas de atuação que o pedagogo pode adentrar, tal como a empresarial, por exemplo, que traz outras especificidades que não serão aqui discutidas.

$3 \bigcirc$ nome deste autor está grafado de diferentes formas nas traduções que temos acesso no Brasil. Assim, utilizaremos a grafia correspondente à obra em questão.

4 Adotaremos a palavra desenvolvente, pois o termo desenvolvimental aplica-se como adjetivo do substantivo desenvolvimento, sendo utilizado em relação à sua avaliação. Desenvolvente é um adjetivo que qualifica o que promove desenvolvimento. $\bigcirc$ substantivo de referência em nossas análises é o ensino, advogamos a adequação do termo desenvolvente. Disponível em: https:// www.dicio.com.br. Acesso em: 14 fev. 2019

5 Ver Duarte (1993), individualidade para si.

6 A psicologia educacional é uma subárea da psicologia que tem como objeto os processos de ensino e aprendizagem em suas relações com o desenvolvimento integral dos indivíduos. Realiza pesquisa básica e avança no conhecimento científico acerca das relações entre psicologia e educação. Subsidia outras áreas envolvidas em processos educativos, especialmente, a pedagogia.

7 A dinâmica figura-fundo é um dos princípios veiculados pela psicologia da Gestalt, segundo o qual toda percepção destaca um foco (figura), delineado pelo campo perceptual do qual emerge (fundo).

8 Para compreensão da tríade conteúdo-forma-destinatário, ver Martins (2013).

9 Não faz parte dos objetivos desse texto, mas não podemos deixar de sinalizar ao leitor que esta concepção de indivíduo e de liberdade individual tem ganhado cada vez mais força com a ascensão da "nova direita" no Brasil e com as necessidades do capital rentista manter o seu poder às custas da vida de qualquer indivíduo (FREITAS, 2018).

10 E que se articulam com projetos políticos de cerceamento da autonomia do professor como o Escola sem Partido (FREITAS, 2018).

11 Evento organizado pelo GEPCO (Grupo de Estudos e Pesquisas em Psicologia Concreta) nos dias 10 e 11 de julho de 2019.

\section{Referencias}

ANTUNES, Mitsuko Antunes. Psicologia e educação no Brasil: um olhar histórico-crítico. In: ANTUNES, Mitsuko Antunes; MEIRA, Marisa Eugênia (Org.). Psicologia escolar: teorias críticas. São Paulo: Casa do Psicólogo. 2003.

BRZEZINSKI, Iria. Pedagogia, pedagogos e formação de professores. São Paulo: Papirus, 1996. 
DAVÍDOV, Vasily. Problemas do ensino desenvolvimental - a experiência da pesquisa teórica e experimental na psicologia. Tradução de José Carlos Libâneo e Raquel A. M. da Madeira Freitas. (Textos publicados na Revista Soviet Education, August, v. 30, n. 8, 1986, sob o título "Problems of developmental teaching).

DUARTE, Newton. O Bezerro de ouro, o fetichismo da mercadoria e o fetichismo da individualidade. In: DUARTE, Newton (Org.). Crítica ao fetichismo da individualidade. Campinas: Autores Associados, 2004.

FIGUEIREDO, Luis Cláudio e SANTI, Pedro Luiz Ribeiro. Psicologia: uma (nova) introdução. São Paulo: EDUC, 2013.

FIRBIDA, Fabíola Batista Gomes; VASCONCELOS, Mário Sérgio. A construção do conhecimento na psicologia: a legitimação da medicalização. Psicologia Escolar e Educacional, Maringá, v. 23, p. 1-9, jun. 2019.

FREITAS, Luís Carlos. A reforma empresarial da educação: nova direita, velhas ideias. São Paulo: Expressão Popular, 2018.

LONGAREZI, Andréa Maturano; FRANCO, Patrícia Lopes Jorge. Atividade pedagógica na unidade significado social-sentido pessoal. In: LONGAREZI, Andréa Maturano; PUENTES, Roberto Valdés (Org.). Fundamentos psicológicos e didáticos do ensino desenvolvimental. Uberlândia: EDUFU. 2017.

LONGAREZI, Andréa Maturano; PUENTES, Roberto Valdés (Org.). Fundamentos psicológicos e didáticos do ensino desenvolvimental. Uberlândia: EDUFU. 2017.

MAGALHÃES, Giselle Modé; MARTINS, Lígia Márcia. Apontamentos sobre a avaliação do desenvolvimento psíquico de crianças na primeira infância. In: FACCl, Marilda Gonçalves Dias; LEONARDO, Nilza Sanches Tessaro; SOUZA, Marilene Proença Rebello. Avaliação psicológica e escolarização: contribuições da psicologia histórico-cultural. Teresina: EDUFPI, 2019.

MAGALHÃES, Giselle Modé. Análise da atividade-guia da criança na primeira infância: contribuições da psicologia histórico-cultural para a avaliação do desenvolvimento infantil dentro de instituições de ensino. Tese de doutorado apresentada no Programa de Pós-Graduação em Educação Escolar. Faculdade de Filosofia e Letras. UNESP Campus de Araraquara, 2016.

MARTINS, Lígia Márcia. O desenvolvimento do psiquismo e a educação escolar: contribuições à luz da psicologia histórico-cultural e da pedagogia histórico-crítica. Campinas: Editora Autores Associados, 2013. 
Onze teses sobre a relação entre psicologia educacional e pedagogia escolar

MIGUEL, Luis Felipe; BIROLI, Flávia. Feminismo e política: uma introdução. São Paulo: Boitempo, 2014.

SAVIANI, Dermeval. Escola e democracia. 34. ed. Campinas: Autores Associados, 2001.

SAVIANI, Dermeval. Pedagogia histórico-crítica: primeiras aproximações. Campinas: Autores Associados, 2001

SAVIANI, Dermeval. A pedagogia no Brasil: história e teoria. 2. ed. Campinas: Autores Associados, 2012.

SOUZA, Marilene Proença Rebello; CUNHA, Beatriz Belluzzo Brando. Projetos de Lei e políticas públicas: o que a psicologia tem a propor para a Educação? In: CONSELHO REGIONAL DE PSICOLOGIA DE SÃO PAULO (Org.). Medicalização de crianças e adolescentes: conflitos silenciados pela redução de questões sociais a doença de indivíduos. São Paulo: Casa do Psicólogo, 2010.

PATTO, Maria Helena Souza. A produção do fracasso escolar: histórias de submissão e rebeldia. São Paulo: Casa do Psicólogo, 1996.

PRESTES, Zoia; TUNES, Elisabeth. 7 aulas de L.S. Vigotski: sobre os fundamentos da pedologia. Rio de Janeiro: E-Papers, 2018.

PUENTES, Roberto Valdés; LONGAREZI, Andréa Maturano. A didática desenvolvimental: seu campo conceitual na tradição da psicologia histórico-cultural da atividade. In: LONGAREZI, Andréa Maturano; PUENTES, Roberto Valdés (Org.). Fundamentos psicológicos e didáticos do ensino desenvolvimental. Uberlândia: EDUFU, 2017.

VIGOTSKY, Lev. Obras escolhidas. Madrid: Visor, 200 1. (Tomo II). 
Profa. Dra. Giselle Modé Magalhães Universidade Federal de São Carlos (Brasil) Departamento de Educação NEEVY (Núcleo de Estudos e Pesquisas sobre a Escola de Vygotski) ORCID: https:/ / orcid.org/0000-0003-4045-7040 E-mail: gisellemagalhaes@ufscar.br

Profa. Dra. Lígia Márcia Martins Livre Docente da Universidade Estadual Paulista (Bauru - Brasil) Programa de Pós-Graduação em Educação Universidade Estadual Paulista (Araraquara - Brasil) Coordenadora do Grupo de Estudos e Pesquisas "Estudos Marxistas em Educação" ORCID: https:/ / orcid.org/0000-0002-4293-9580 E-mail: ligia.martins@unesp.br

Recebido 30 out. 2019 Aceito 28 nov. 2019 